\title{
Small and Safe
}

\section{Rathna N. Koman}

School of Law, Singapore Management University, Singapore, Singapore

Email: rathnakoman@smu.edu.sg

How to cite this paper: Koman, R. N. (2017). Small and Safe. Beijing Law Review, $8,551-569$.

https://doi.org/10.4236/blr.2017.84030

Received: November 24, 2017

Accepted: December 26, 2017

Published: December 29, 2017

Copyright $\odot 2017$ by author and Scientific Research Publishing Inc. This work is licensed under the Creative Commons Attribution International License (CC BY 4.0).

http://creativecommons.org/licenses/by/4.0/

\section{Abstract}

This paper seeks to address issues relating to the management of child protection in Singapore context. Currently the system provides an institutionalized multi-disciplinary approach to protecting children. The current integrated system of handling child abuse is comprehensive and thorough and seeks to serve the best interests of the child. However given socio economic and legal ramifications of child abuse, this paper proposes the following enhancements in the management of child protection. First reporting of child abuse should be made mandatory similar to the American model. Failure to do so should constitute an offence under the Children and Young Persons Act and to be punished appropriately. Second, educators, preschoolers or otherwise should undergo compulsory and centralized training in the management of child protection, since the state has undertaken responsibility in protecting children from abuse. Given the complexities of recognizing the varying degrees of signs and symptoms of child abuse, practical training is recommended for educators in addition to the sector specific screening guide currently used. Third, such training can be conducted by specialists in Singapore, Ministry of Social and Family Development, (MSF) and the training can be calibrated according to different levels of educators. Fourth, it is important to have continuous training and refresher courses to ensure that educators are up to date. Fifth, curriculum of preschoolers must include education/awareness of child abuse so that the young can act as the first line of defense for child abuse. Additionally the curriculum should also focus on programs that cultivate openness in children, and the ability to express emotions or not to suppress them as a sign of embarrassment or shame in cases of child abuse. Last but not least, a National Registry for Child Abuse should be set up. This should be accessible to designated individuals of seniority in MSF, police, healthcare professionals and principals of schools or senior designated educators/administrators etc. A registry with such accessibility will amongst others facilitate safe recruitment practices in schools, enhance response time for protection, enable informed 
reporting etc.

\section{Keywords}

Managing Child Protection, Child Abuse, Child Protection Service, Mandatory Reporting, Child Abuse Registry

\section{Introduction}

Small and safe is a literal translation of "litenochtrygg", (Brottsoffermyndigheten, 2015) a project that was started in Sweden so as to raise child awareness and their rights, recognizing the need for special safeguards and care, including appropriate legal protection, given a child's physical and mental immaturity. ${ }^{1}$

This paper seeks to address some issues relating to the management of child protection particularly in the area of child abuse/maltreatment ${ }^{2}$ in the Singapore context. Child abuse is a serious issue. Currently the system in Singapore, legal or otherwise, provides an institutionalized multi-disciplinary approach to protecting and managing abused children. In brief, first, Singapore has a child protection service (CPS), which has an integrated system of handling child abuse and protection. CPS is responsible for the management and protection of a child in the event of an abuse. Second, there are various legislations providing for the protection of a child with appropriate sanctions/punishments in the event of an abuse. Third, the Courts have been vigilant in the enforcement of the protection rights of the child and continue to impose deterrent sentences on perpetrators. These are elaborated in the later sections of the paper.

Section 5 of Children and Young Persons Act defines ill treatment of a child or a young person (CYP) as when a person who has custody, charge or care of that child or young person subjects him/her to physical or sexual abuse, does or causes acts that which endangers the safety or is likely to endanger the safety, causes or is likely to cause unnecessary physical pain, suffering or injury, injury to emotion, health or development or willfully neglects, abandons or exposes the child to harm. To put it simply, it covers all forms of physical and/or emotional ill treatment, sexual abuse, neglect, negligent treatment, including exploitations that result in actual or potential harm to a child's health, development or dignity (The Statutes of the Republic of Singapore, Children and Young Persons Act).

Based on the statistical data of Ministry for Social and Family Development (MSF) it was reported in The Straits Times (Tan, 2017) that cases of child abuse

${ }^{1}$ Refers to the guiding principles of child protection in the Preamble of UN Convention on the Rights of the Child, (UNCRC) adopted by the General Assembly resolution 44/25 of 20 November 1989 and entered into force on $2^{\text {nd }}$ September 1990, in accordance with Article 49. The preamble states amongst others that "...the child, by reason of his physical and mental immaturity, needs special safeguards and care, including appropriate legal protection before as well as after birth", UNCRC, preamble.

${ }^{2}$ Hereinafter child abuse is used to generically refer to child abuse and/or maltreatment. 
have been on the rise. ${ }^{3}$ Based on these reports, the ages of the children abused have ranged from a baby to under 16 (Tan, 2017). Based on this statistical report it was stated that since most of the children were of the school going age, the peak ages of the children corresponded to the transition period between primary and secondary schools (Ngiam, Kang, Ramkumar, King \& Chung, 2015). Hence suggesting that school was a "significant stressor to the parent child relationship in the Singapore setting" (Ngiam et al., 2015). Second, based on September 2017 reports, nearly $40 \%$ of the abused in the last three years were under seven (Goy, 2017), hence putting the spotlight on preschoolers and responsibilities and obligations of educators in these sectors in the management of child protection.

\section{Importance of Dealing with Child Abuse}

The CYPA defines a child as a person below the age of 7 and a young person as 14 or above and below 16. Both are availed equal protection from abuse under the Act. Whereas the United Nations Convention on the Rights of the Child (UNCRC) defines a child as every human being below the age of 18 unless under the law applicable the child reaches majority earlier (United Nations Convention on the Rights of the Child, 1989).

UNCRC makes it clear that in its preamble that children must be provided a safe and a nurturing environment free of abuse so as to allow them to grow into healthy individuals, physically, emotionally and mentally (United Nations Convention on the Rights of the Child, 1989). The reasons for such a provision are obvious. Failing to address child abuse has socio-economic costs for the child and the society as a whole (Ngiam et al., 2015). It has been noted that child abuse “...predisposes the child to multiple long lasting effects, including mental health problems which in some cases can have lifelong implications and associated costs" (Ngiam et al., 2015: p. 613).

Second this would in turn lead to long lasting social and economic repercussions. The latter relates to costs of interventionists measures that needs to be undertaken by the State and an abused victim not being an effective economic contributor. To accentuate the problem Singapore has a rapidly aging population. Hence every healthy child, mentally, emotionally and physically count towards the growth of the country in more than one way. We cannot deny the child being an important socio economic contributor in this calculus.

We have to be mindful of the economic costs incurred in rectifying the negative impacts of child abuse. Sooner the child abuse is identified and appropriate measures taken, lesser the economic costs incurred. This requires amongst others effective measures of detection and reporting. The price to rectify negative impact of child abuse, if at all possible, only increases for the society and the

${ }^{3}$ In 2016, it was reported that of the cases reported to MSF, 873 cases of child abuse cases were probed. This was reported to be $50 \%$ more than 2015 which was 551 cases. In 2014, 381 cases were investigated. It has been stated by MSF spokesperson that the increase in figures were due to more rigorous screening tools introduced by MSF to improve detection, reporting and management of child abuse cases. See also Goy (2017), where it was reported that of the reported cases nearly $40 \%$ of the children were below 7 years of age. 
child if not appropriately and/or soon resolved (Kansas Department for Children and Families, Revised 2016). It has been stated in the High/Scope Perry Preschool Study, "that every dollar spent on prevention saves $\$ 7$ on intervention services" (Kansas Department for Children and Families, Revised 2016).

Additionally, it becomes imperative to continually assess the efficiency and effectiveness of education, prevention and intervention measures in the management of child protection.

Singapore became a signatory of the UNCRC in October 1995. By this ratification, Singapore has assumed State responsibility towards protecting children, amongst others. ${ }^{4}$ Four core principles ${ }^{5}$ underlie the rights of the child in UNCRC (United Nations Convention on the Rights of the Child, 1989). Of the four, two of the core principles ${ }^{6}$ directly relate to management of child protection. Article 3(1) UNCRC, clearly states that in all actions concerning children, the best interests of the child shall assume primary consideration and 3(2) UNCRC states that a state shall take all appropriate legislative and appropriate measures to ensure child protection and care. Second Article 19(1) UNCRC makes it obligatory for a State to take all appropriate legislative, administrative, social and educational measures to protect the child from all forms of child abuse and by Article 19(2) UNCRC such protective measures where appropriate should include effective procedures for the establishment of social programmes to provide necessary support for the child and care givers, as well as for prevention and for identification, reporting, referral, investigation, treatment etc. (United Nations Convention on the Rights of the Child, 1989).

UNCRC clearly recognizes that "the child, by reason of his physical and mental immaturity, needs special safeguards and care, including appropriate legal protection before as well as after birth...".

Singapore for its part has complied with its obligations under UNCRC and in some areas has gone beyond the call. This is evidenced in the following section. However given the socio economic ramifications of child abuse, this paper proposes the following enhancements, legal or otherwise in management of child protection. First reporting of child abuse should be made mandatory and failure to report should constitute an offence under the CYPA, to be punished appropriately. Second, educators, preschoolers or otherwise should undergo compulsory and centralized training in the area of management of child protection. Third, such training can be conducted by specialists in MSF and the training can be calibrated according to different levels of educators. Fourth, it is important to have continuous training and refresher courses to ensure that educators are up to date on the management of CYP protection.

Fifth, curriculum of preschoolers must include cultivating awareness of child

${ }^{4}$ Refer to UNCRC, Preamble, Article 2 and 19.

${ }^{5}$ The 4 core principles are 1) non-discrimination, 2) acting in the best interests of the child, 3) survival, development and protection and 4) participation.

${ }^{6}$ This would be acting in best interests of the child and ensuring survival, development and protection.

${ }^{7}$ Stated in the Preamble of UNCRC. 
abuse such as training them to recognize appropriate and inappropriate touching so that a CYP can act as the first line of defense for child abuse. Additionally the curriculum should also focus on programs that cultivate openness in children, and the ability to express emotions or not to suppress them as a sign of embarrassment or shame in cases of child abuse.

Last but not least, a National Registry for Child Abuse should be set up. This should be accessible to designated individuals of seniority in MSF, police, healthcare professionals and principals of schools or senior designated educators/administrators etc. A registry with such accessibility will amongst others facilitate safe recruitment practices in schools, enhance response time for protection, enable informed reporting, amongst others.

\section{Current State of Affairs in Singapore}

A perusal of the Singapore system, legal or otherwise for CYP protection, outlined below will demonstrate that it has been vigilant, prompt and effective in enforcing its state obligations under UNCRC. As a matter of fact there has been a continuous review to improve the child protection system, protection rights of these vulnerable victims, proposing new laws to enhance protection of CYP during the criminal process and punishment of offenders, imposition of deterrent and retributive sentencing of offenders of CYP by the courts etc. These improvements deal with $21^{\text {st }}$ century issues relating to CYP.

\subsection{Child Protection Service (CPS)}

Currently Singapore has an institutionalized integrated multi-disciplinary approach towards management of child protection. The current integrated system of handling child abuse is comprehensive, thorough and seeks to serve the best interests of the CYP through the joint efforts of all relevant agencies and professionals.

In summary child protection system in Singapore is guided by a three level pyramid system, involving the State, specialized partners and the community. Seriousness of concern and need for intrusive measures/interventions dictate the level of attention to be given. At the most serious level where serious injury, severe neglect or sexual abuse is detected, the State's CPS and the law enforcement agencies are concurrently invoked. At the middle level where neglect, excessive discipline or inadequate medical care is detected, community based child protection specialists' centres and family violence specialists' centres are called upon (Ministry for Social and Family Development, 2016b). For the last rung, community agencies are invoked if there are situations of high family stress, emotional or economic stress etc. These are well known "at risk" categories that can elevate the concern to most serious level. Engaging them at this point may prevent escalation to a higher level at a later stage. This is a move in the right direction.

Where CPS and the police are involved the system provides for a detailed follow up to ensure safety of the CYP and assistance to families in the most appro- 
priate manner (Ministry for Social and Family Development, 2016b: pp. 10-15). ${ }^{8}$ In summary, the moment the matter is within CPS, a child protection officer (CPO) is assigned. Social and criminal investigation is done concurrently. The $\mathrm{CPO}$ conducts the investigation and reports to Child Abuse Protection Team (CAPT). This team uses the multi-disciplinary case conference approach to assess the findings and ascertain the risk to the victim (Ministry for Social and Family Development, 2016b: p. 12). It will recommend goals and plan for the victim and the family. The progress of the case is reviewed by the Child Abuse Review Team (CART) (Ministry for Social and Family Development, 2016b: pp. 10-15). The latter ensures that the safety and service plans for the victim and the family are abided and that the intervention measures provide a "safe, stable and permanent care plan" for the victim.

The social intervention measures laid out by CPS are there to ensure protection of the victim whilst the matter concurrently progresses through the criminal legal process. Second, the abovementioned system ensures adoption of best practice standards for management of child protection and that such management is prompt and takes into account the best interests of the child. Third, standards adopted ensure transparent and effective coordination of the roles and responsibilities of various stakeholders involved in the management of child protection (Ministry for Social and Family Development, 2016b). Such a system attempts to ensure that no one falls through the cracks, if any and prompt and protective action is taken without delay. Last, the system has a structured decision making process (Ministry of Social and Family Development, 2015) for the abuse reporters to invoke the CPS machinery without delay.

\subsection{Handling Abused Children with Kids' Glove}

The system understands the trauma of child abuse and hence ensures that processes are in place for inter-agencies to handle the victims in the most appropriate manner (Ministry of Social and Family Development, 2016a). ${ }^{9}$ For instance, where the investigation takes place at the school, the interview and the examination will be done in a private room to ensure privacy. Additionally it will be done in the presence of the teacher whom the child feels comfortable (Ministry for Social and Family Development, 2016a). Such a practice provides support and encouragement. In certain situations the child is referred for counselling (Ministry for Social and Family Development, 2016a: p. 26). Where the investigation takes place at the hospital, a women police officer trained in victim

${ }^{8}$ This would involve engaging specialists of different disciplines so as to tap their resources and advice to enable an informed decision on the risk and care of CYP.

${ }^{9}$ These National Standards sets the framework for the management of child protection in Singapore and describes the referral standards required by the different sectors involved. The Standards evidence transparency in processes between inter agencies in the management of child protection. There is also a Manual for the Management of Child Abuse that was launched in 1999 and revised in 2003. Apparently the Manual outlines the roles and responsibilities of each stakeholder and the intervention measures required under outlined circumstances. However it appears that the Manual is only accessible to relevant partners and stakeholders and not accessible to the public as a whole. At the time of writing this paper, I could not access this manual and therefore in a position to comment. 
counselling will be assigned to escort the child for medical exam (Ministry for Social and Family Development, 2016a: p. 20). In cases where the investigation officer conducts the interview, the victim will be interviewed in the presence of a women police officer. The latter will also become the victim's counsellor and confidante throughout the police investigation (Ministry for Social and Family Development, 2016a).

Further recent amendments to the Criminal Procedure Code (“CPC") have been proposed with respect to handling of vulnerable victims in the criminal process (The Statutes of the Republic of Singapore, Criminal Procedure Code). Currently the law requires all statements taken by law enforcement agencies to be in writing. It is noteworthy that amendments are proposed to allow statements to be taken via video recording for vulnerable victims (Singapore Ministry of Law, 2017). Such recordings are proposed to be used in place of oral evidence in chief to reduce the trauma faced repeatedly in recounting the ordeal (The Statutes of the Republic of Singapore, Evidence Act). Amendments have also been proposed to enhance protection of sexual and child abuse offence complainants during the criminal process. ${ }^{10}$ First complainant's identity is to be automatically protected from publication the moment the offence is reported (Singapore Ministry of Law, 2017). Second, in camera (closed door) hearings to be automatic when such victims testify. Third, physical screens to shield the victims from the perpetrators when the former is giving evidence in court. This is to protect them and prevent the probative value of the evidence from being affected due to victim's fear or distress. Last, complainants should not be asked questions on their sexual history or activities, including appearance or behavior other than that to which the charge relates without leave of court (Singapore Ministry of Law, 2017). This would also bar evidence being adduced to this end. These amendments seek to increase the protection of vulnerable victims in the criminal process so as to facilitate a fair balance in an adversarial criminal process (Singapore Ministry of Law, 2017).

\subsection{Principle Legislation Governing Child Abuse and Offences against CYP}

Laws criminalizing offences against CYP are comprehensive and thorough. This would include generic offences against the child or young persons and specific provisions relating to abuse.

There are couple of laws dealing with child protection and/or the management thereof. The principle legislation criminalizing abusive acts against CYP is CYPA (The Statutes of the Republic of Singapore, Children and Young Persons Act). This Act, amongst others provides for the welfare, care, protection and rehabilitation of CYP in need of care, protection or rehabilitation. As stated earlier this legislation defines when a person is considered a CYP ${ }^{11}$ and what constitutes

\footnotetext{
${ }^{10}$ The amendments proposed will necessitate changes in Parts XII and XIV of the CPC and the certain provisions of the Evidence Act (Chapter 97).

${ }^{11}$ Interpretative section of CYPA.
} 
ill-treatment ${ }^{12}$ in detail under Part II of the Act (The Statutes of the Republic of Singapore, Children and Young Persons Act). All cases of child abuse under police investigation are classified under section 5 of CYPA. ${ }^{13} \mathrm{~A}$ person punished under this provision faces a maximum penalty of 7 years imprisonment and/or fine of $\$$ S20,000 maximum, in cases where death is caused. Otherwise a maximum of 4 years imprisonment and/or fine of $\$$ S4000. ${ }^{14}$ CYPA also provides the framework for intervention in cases of abuse and also outlines the parameters of protector, courts and police powers etc. (The Statutes of the Republic of Singapore, Children and Young Persons Act). With respect to reporting, section 87 of the CYPA states that a person who is aware or has reason to suspect that a child or young person "...is in need of care or protection may make a notification to the Director or a police officer of the facts and circumstances on which his knowledge or suspicion is based." ${ }^{15}$ Where such report is made "in good faith", the reporter shall be immune from liability, civil and criminal and will not be regarded as having breached any code of professional etiquette or ethics or any other professional conduct. ${ }^{16}$ Additionally the identity of the informant shall be kept confidential. ${ }^{17}$ These provisions make it conducive for an informant to report against child abuse without suffering repercussions provided the report has been made in good faith (The Statutes of the Republic of Singapore, Children and Young Persons Act).

Other notable statutes in this area are the Women's Charter, Early Childhood Development Centres Act 2017 (ECDA), and the Penal Code.

The Women's Chartercovers provisions relating to protecting children from family violence, ${ }^{18}$ spells the duty to maintain $\mathrm{CYP}^{19}$ and offences against women and girls (The Statutes of the Republic of Singapore, Women's Charte). ${ }^{20}$

The Penal Code (PC) provisions on the other hand has generic and specific provisions criminalizing offences against CYP (The Statutes of the Republic of Singapore, Penal Code). All generic offences against persons, such as murder ${ }^{21}$, culpable homicide ${ }^{22}$, kidnapping ${ }^{23}$, abduction ${ }^{24}$, grievous hurt ${ }^{25}$, hurt ${ }^{26}$, aggravated hurr ${ }^{27}$ etc., likewise apply to CYP victims. The PC also has specific provisions

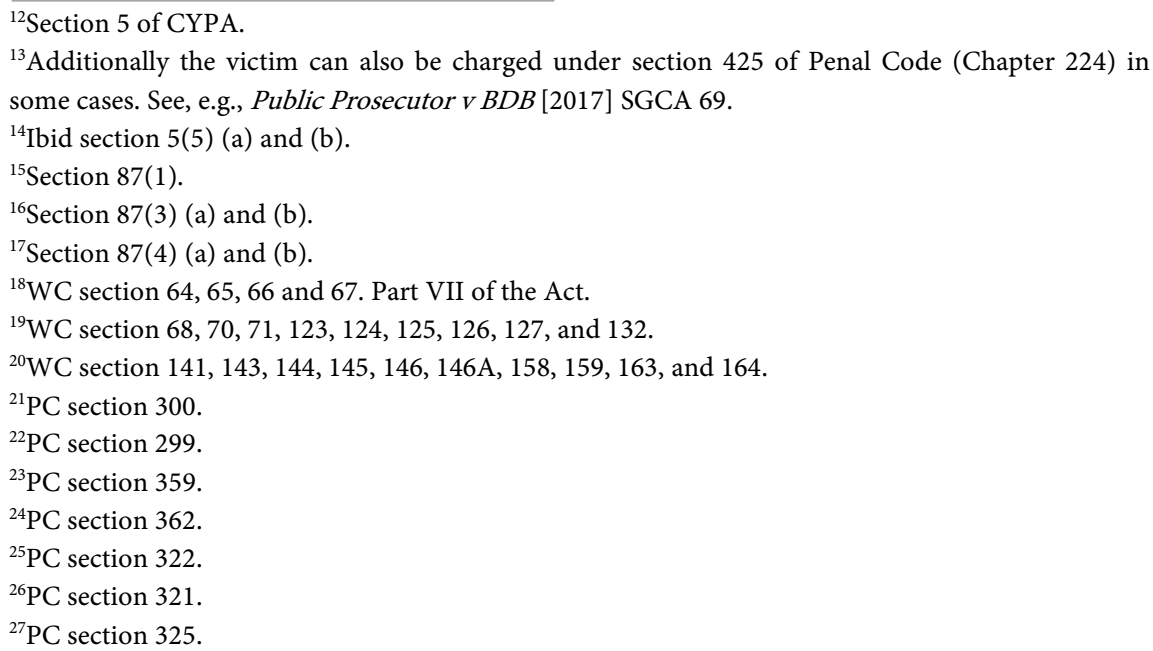


which relate to CYP such as infanticide ${ }^{28}$ abetment of suicide of child, ${ }^{29}$ child destruction before or immediately after birth, ${ }^{30}$ exposure and abandonment of children under 12 years of age by parent or care-giver, ${ }^{31}$ disposal of dead body of a child ${ }^{32}$ kidnapping from lawful guardianship ${ }^{33}$, abduction, ${ }^{34}$ kidnapping or abducting a child under 10 years with intent to steal moveable property, ${ }^{35}$ selling and buying minors for purposes of prostitution, ${ }^{36}$ sexual penetration of a minor, ${ }^{37}$ commercial sex with minor under 18 in or outside Singapore, ${ }^{38}$ sexual grooming of minor under $16^{39}$ etc. (The Statutes of the Republic of Singapore, Penal Code). These are only some of the offences against CYP and they are extensive and comprehensive in coverage and protection of CYP. Singapore has been active and forward thinking in criminalizing new forms of offensive activities against CYP in the last ten years, such as the sexual grooming provision and engaging in commercial sex with minors under 18 in or outside Singapore, including touring outside Singapore for commercial sex with minor under 18 (The Statutes of the Republic of Singapore, Penal Code).

The ECDCA is a new Act passed in February 2017. This Act is concerned with regulating operation of early childhood development centres such as childcare centres and kindergartens to higher and more consistent quality standards across early childhood education sector (The Statutes of the Republic of Singapore, Early Childhood Development Centres Act 2017). Amongst others, it provides for a new licensing framework for pre-schools ${ }^{40}$ and approval is required from Early Childhood Development Agency ("the Agency") should third party education providers be engaged. ${ }^{41}$ The approval process is really to vet the suitability of these providers in working with young children. Penalties have also been introduced under this framework to penalize errant pre-schools (The Statutes of the Republic of Singapore, Early Childhood Development Centres Act 2017). The penalties range from fines ${ }^{42}$ to shortening license tenures coupled with immediate remedial action and if necessary in appropriate cases revocation of license (The Statutes of the Republic of Singapore, Early Childhood Development Centres Act 2017). Additionally more powers are given to the Agency for

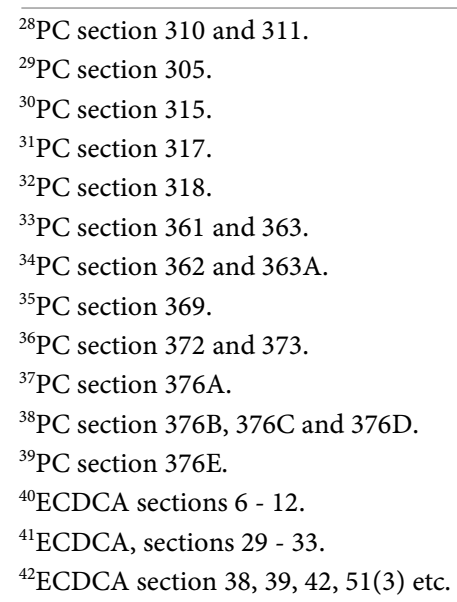


investigating errant practices in this sector. ${ }^{43}$ However the Act has decriminalized administrative lapses (The Statutes of the Republic of Singapore, Early Childhood Development Centres Act 2017).

Having regard to the above, it is patent that laws protecting the child's best interests and criminalizing offences against CYP has been effective and forward thinking. Nonetheless, recommendations are made in part IV of the paper to enhance the management of child protection in Singapore.

As for Singapore courts, it has always taken a strong stance on crimes against CYPs. At the time of writing this paper, it is noteworthy to mention that in the case of Public Prosecutor $v B D B$, the Court of Appeal had urged legislative reform to afford the courts the power to impose enhanced penalties, one and half times the prescribed maximum penalty to offenders for offences against vulnerable victims, i.e. CYP. This request arose from a case where the mother had abused the child of 4 years until the latter died of his injuries. She was initially sentenced to an aggregate term of 8 years imprisonment. On appeal the sentence was raised to an aggregate sentence of 14 years and six months. It was stated that "deterrence was a weighty consideration in offences against young victims given the gross physical disparity between the victim and the offender in such cases... the court also held that a parent who betrayed the ultimate relationship of trust and authority between a parent and his or her child stood at the furthest end of the spectrum of guilt..." (Public Prosecutor v BDB, 2016, at [16]-[24]). For avoidance of doubt, for purposes of sentencing, an offender who has abused CYP is seen as more culpable and deserving a sentence at the higher spectrum of the punishment. Abusing a CYP is always seen as an aggravating factor in sentencing calculus. ${ }^{44}$ Factors taken into account for aggravation are deliberation or premeditation of attack, manner and duration of attack, victim's vulnerability, use of weapon, group assault where applicable, offender's antecedents and prior intervention by the authorities (Public Prosecutor $v$ BDB, 2016, at [28]-[31]). Offenders charged under section 325 of PC for causing grievous hurt to a CYP also have had the maximum sentence of 7 years imposed..$^{45}$ Where multiple charges are made against an offender, under the law, the judge can allow the sentence to run consecutively for some of the charges. ${ }^{46}$ The primary sentencing consideration for section 325 of PC and/or section 5 of CYPA is premised on deterrence and retribution (Singapore Parliamentary Debates, 1993). The actual extent of the sentence will be guided by the extent of the seriousness of the injury, culpability of the offender and other relevant circumstances. Where death of CYP is caused, the likely sentence will be the imposition of maximum penalty under the provision (Public Prosecutor $v$ BDB, 2016, at

\footnotetext{
${ }^{43}$ Prior to ECDCA, the authorities were only allowed to inspect premises of errant operators in this education sector. By this Act, the Agency can investigate errant practices of these schools, have powers to search, interview and record the investigation process. ECDCA, section 37.

${ }^{44}$ See, e.g., Purwanti Parji V PP [2005] 2 SLR(R) 220, PP V AFR [2011] 3 SLR 833, PP V Firdaus bin Abdullah [2010] 3 SLR 225 etc.

${ }^{45}$ See, e.g., PP v Firdaus bin Abdullah [2010] 3 SLR 225.

${ }^{46}$ Section 307 CPC.
} 
[26]-[27]).

\subsection{National Licensing of Sports Coaches}

In the area of sports, currently Singapore has taken some safeguards against sexual abuse by coaches (Sport Singapore, 2017). We do have a national registry for coaches (NROC) $)^{47}$ but it is not obligatory for coaches to register. However a coach who is registered must declare any convictions, disciplinary proceedings, dismissals, discharges, complaints or police investigations. To be eligible to register, a coach must complete a course in values and principles in sports (Sport Singapore, 2017). This course does include a segment in teaching the right of youth to play sports free of abuse (Sport Singapore, 2017). Hence membership does have a twin fold purpose of ensuring safe recruitment practices and advocating and educating coaches against child abuse. In cases of breach, the coach can be suspended (Sport Singapore, 2017). Though this is a move in the right direction some recommendations are made in the next segment for further improvement in this area.

\section{Issues}

\subsection{Mandatory Reporting}

\subsubsection{Current Position}

Educators ${ }^{48}$ play an important role in the management of child protection. Educators have an ethical and a moral role in identifying, preventing and responding to child abuse and neglect for various reasons. First they have consistent and close access to students and for a substantial period of the day compared to other professions. Hence this gives them the valuable opportunity to observe any changes in behavior, appearance etc. Second, an educators training does enable them to detect indicators of child abuse. Third, the role of an educator is to encourage learning. This cannot be achieved if a CYP is subject of ill-treatment. Hence an educator has a responsibility to remove barriers to efficient learning outcomes.

Accordingly educators have a greater responsibility towards CYP in their care. ${ }^{49}$ The moral and ethical responsibility must translate into a clear mandatory responsibility to report in cases where abuse is detected or suspected. Currently section 87(1) CYPA allows an individual to report, however the use of the word, "may" is suggestive of a non-mandatory obligation and therefore failure to report does not amount to an offence. Where an individual chooses to report, it is ${ }^{47}$ Sport Singapore is a statutory board of the Ministry of Culture, Community and Youth created $\mathrm{NRO}$ in 2003 to raise the standard and professionalism of sports coaching in Singapore. It serves to ensure minimum technical qualification of sport coaches, to ensure that practicing coaches continue to improve and that coaches provide a safe environment for their athletes. The national registry may be accessed at

https://www.sportsingapore.gov.sg/athletes-coaches/coaches-corner/national-registry-of-coaches.

${ }^{48}$ For purposes of this paper, educators would include teachers, education professionals, counsellors, school social workers and other school personnel who interact with CYP.

${ }^{49}$ After all, teaching is seen and advertised in the Singapore context as a "calling" as opposed to mere vocation or profession. See also Singapore Ministry of Education (2017). 
made in accordance with the procedure laid down in the sector specific screening guide, mentioned earlier.

Given the role of an educator and the fact that schools are well placed as an educational institute, this obligation to report must be mandated where child abuse is detected or suspected. Failure to report child abuse must constitute an offence under CYPA. The punishment for failing to report can be appropriately calibrated. It can range from a fine to community based sentencing ${ }^{50}$ or even an imprisonment term depending on the reasons for failing to report.

In America, for instance in Kansas reporting of child abuse or suspected child abuse is mandatory for educators, school administrators or other employees of the educational institute (Kansas Statues, 2012). The report can be made orally and if requested followed with a written report to the department of social services and if not open on the day of report it should be made to the Secretary of the department (Kansas Statues, 2012). Willful and knowing failure to report is a class B misdemeanor in Kansas City (Kansas Statues, 2012).

\subsubsection{Need for Mandatory Reporting}

There are so many reasons for mandating reporting. Other than the reasons mentioned above, educators can and should be trained to detect indicators of child abuse. If so, this will result in prompt reporting of abuse which will result in prompt protective action of the CYP.

Additionally the sooner child abuse is resolved, the lesser the socio economic costs to society, CYP and the costs of intervention measures. Besides the number of child care operators private or otherwise is on the rise. Accordingly the number of CYP under the care of educators is also increasing. Mandatory reporting would increase the chance for early detection in cases of abuse.

Making the obligation mandatory only augments the state's responsibility to act in the best interests of CYP and managing effective protection. The state via CPS is managing an effective system for protection of CYP. However the state is much dependent on reporters to carry out its obligation to protect CYP. Hence reporting becomes fundamental to the protection of a CYP. The fact of the matter is that child abuse is a societal problem with wide ramifications as stated earlier (Ngiam et al., 2015). Hence educators must realize that they have an equal responsibility towards management of child protection. Mandatory reporting will promote a culture of active gate keepers. For avoidance of doubt mandatory reporting will only impact those who are not currently inclined to report ${ }^{51}$ notwithstanding the signs and symptoms of child abuse.

\footnotetext{
${ }^{50}$ Community based sentences are given for offences in the rehabilitative spectrum of the offences. Community based sentencing will include, community service orders, community work orders etc. See sections 335-354 CPC.

${ }^{51}$ There could be many reasons why educators may not want to report. For example, It could be that they are unsure of their obligations to report or unsure/unaware of the legal consequences of reporting or have an attitude of not wanting to get involved or may not want to get involved if the parents of the victim are known to the educator personal or otherwise, or educator does not want to report if the parent is someone known in society or for any other reasons.
} 
One must be mindful that the obligation to report in good faith only kicks in when there are signs of child abuse or it is suspected. It does not require the mandated reporter to make a final determination of the abuse. That would be ascertained by CPS and the police, if the latter is invoked. Some educators are unaware of this distinction and the extent of their duty to report. It is important to be aware that the responsibility to report is divorced from the responsibility to determine child abuse in fact. In these circumstances, it is clearly not an onerous duty to comply.

Further CYPA protects the informant in all manner when the report is made in good faith. CYPA clearly protects the informant's identity and even protects him/her from civil and criminal responsibility, when acting in good faith. ${ }^{52}$

Mandatory reporting sets the tone amongst educators the seriousness of child abuse. Besides such mandatory reporting makes it clear to an educator that employer policies cannot supersede statutory obligations to report.

\subsection{Specialist Training of Educators in Management of Protection of CYP}

\subsubsection{Should Be Compulsory and Centralized}

Specialized and centralized compulsory practical training must be conducted for educators in the management of protection of children. Currently such training is not conducted. Such training can focus on the signs and symptoms of child abuse and management of abused CYP for educators. The curriculum and training program, online-or otherwise, can be approved by the MSF specialists given their expertise and knowledge in this area. The training can be calibrated to suit different levels of educators. An appropriate costs model between the state and the school can be worked out given that child abuse is a community concern. As indicated earlier, educators must take an equal responsibility for preventing and detecting child abuse. Should costs be an issue we can advocate on-line training and quiz to test their knowledge as is currently done in the state of California (California Penal Code, Child Abuse and Neglect Reporting Act). ${ }^{53}$ Their on-line mandated reporter training, structured into 5 lessons with sample videos appears to be well thought, conducted and efficient. With a quiz on tow makes the learning effective and the scores at the end of the quiz indicate the level of educators understanding of the material. Such on-line training is practical and cost effective. Should we proceed along the lines of the on-line quiz, perhaps an educator must be required to state as a pre-condition the score attained prior to recruitment or as part of continuous learning/training in this area.

It is important that the training so offered must have continuity or refresher courses as child abuse is an evolving area and the educators working with CYP

${ }^{52}$ CYPA sections 87(3) (b) and 87(4).

${ }^{53}$ The CANRA on-line mandatory reporter training can be found at http://educators.mandatedreporterca.com/intro/introl.htm. The personnel on-line test can be found at http://www.surveygizmo.com/s3/2948427/School-Personnel-Final-Test. 
must be kept abreast of developments in this area. Currently there is no requirement for an educator to do refresher courses in this area. Likewise such refreshers can be conducted on-line.

Educators must have clear knowledge of the following if they are expected to participate actively in the management of child protection:-

- What constitutes signs and symptoms of child abuse with live examples;

- The duty to report child abuse;

- Extent of the duty to report;

- When to report;

- Who to report;

- How to handle CYP subject of abuse.

- Socio economic consequences to the child and the society and costs of intervention measures.

Of the last, by becoming aware of the wide ramifications of child abuse, it is more likely than not that educators will take ownership of their role in the management of child protection. There must be an awareness amongst educators that they have an obligation to know how to protect a CYP from harm. Educators play an indispensable role in the fight against child abuse. However they need to be empowered in their fight against child abuse and for that training as suggested above is essential.

Currently in cases of early childhood development centres, pursuant to section 26(1) and (3) of ECDCA, in granting approval for "a licensee to perform or an individual to be deployed to perform any prescribed duty .... at an early childhood development centre, the chief licensing officer may impose such conditions as he considers requisite or expedient..." and that "...may include the training and passing of examinations or tests" etc. Hence courses on management of child protection are currently not mandatory unless and otherwise imposed as a condition for grant of a license.

\subsubsection{Reasons}

There are various reasons for having such a centralized system of training for educators in the area of child abuse. It is important to ensure consistency in the training of educators given that the report of child abuse comes to CPS for action and review.

As stated earlier, $40 \%$ of the reported cases of child abuse victims are below 7 and it has been reported that experts are of the view that "pre-schools have been found to be inadequate in spotting signs of child abuse" (Goy, 2017).

The sector specific screening guide (SSSG) though useful with signs and symptoms of child abuse and the requirements to be satisfied for different trigger level in CPS (Ministry for Social and Family Development, 2016b), it can be difficult to cross the bridge between theory and practice. Perhaps, practical lessons coupled with training videos followed by SSSG and an on-line quiz may assist in the better understanding of child abuse and its management by educators. 


\subsection{Curriculum of Pre-Schoolers}

\subsubsection{Current}

The current school curriculum is innovative, "comprehensive, balanced and developmentally appropriate" (Ministry of Social and Family Development, 2003). ${ }^{54}$ However the current learning outcomes do not include the need to create an awareness about child abuse amongst children.

\subsubsection{Way Forward}

An educator is responsible for the well-being of a child. Hence it is important to add prevention programs in creating an awareness about child abuse (U.S. Department of Health and Human Services, 2003). CYP need to be informed and empowered on what constitutes appropriate and inappropriate touching. Educating CYP is the first line of defense against child abuse. To this end, America has been a trail blazer in inculcating the appropriate skills in CYP curriculum for various needs, some of which deserve mention here (U.S. Department of Health and Human Services, 2003).

In America, children are informed on the basics of good, bad and confusing touches and are trained to recognize these touches (U.S. Department of Health and Human Services, 2003). They are also encouraged to express their feelings relating to those touches. It has been said that such training and encouragement of expression may help a CYP to be confident and comfortable in talking about inappropriate touching (U.S. Department of Health and Human Services, 2003: p. 11).

It was interesting to note from a 3-year study funded by the U.S. Department of Education, that adding conflict management and peer mediation skills in the curriculum in middle schools, reduced chronic disruptive and aggressive behavior in CYP and decreased disciplinary problems in schools (U.S. Department of Health and Human Services, 2003). It was also noted in this study that such behaviors were noted in CYPs subject of child abuse or are from at-risk families, who were prone to acting out behaviors (U.S. Department of Health and Human Services, 2003: p. 46). Advocating a curriculum that deals with such behavior facilitates an educative, preventative ${ }^{55}$ and rehabilitative approach towards abused CYPs (U.S. Department of Health and Human Services, 2003).

Next, cooperative learning in the context of relating to peers coupled with conflict resolution and problem solving skills allows a CYP to relate adequately with peers (U.S. Department of Health and Human Services, 2003). Socialization skills such as journal writing is increasingly used in curriculum as it allows a child to compose their thoughts, express feelings and gain self-awareness (U.S. Department of Health and Human Services, 2003: pp. 45-46). These are advocated as school based programs. Such programs may be useful in identifying

\footnotetext{
${ }^{54}$ See also p. 35 for the designated learning outcomes of the programs for the children. These are regularly evaluated to meet the goals of the curriculum.

${ }^{55}$ Preventative as it is a well-known fact that often abused CYPs may become abusive parents themselves.
} 
child abuse situations, in cases where a CYP is completely closed to discussing with an educator the perils of child abuse existent in the home environment.

\subsection{Registry for Child Abuse/Maltreatment}

\subsubsection{Current}

A child abuse register was introduced in 1998 so as to facilitate and enhance investigations by agencies involved in the management of child abuse (Goh, 2011). The idea was to flag to the police and healthcare professionals possible incidences of child abuse. The register is used as database for reference checks for known and previously reported cases (Goh, 2011: p. 19). However this register is limited in access to certain individuals. This register is not considered as a Child Abuse Registry (U.S. Citizenship and Immigration Services, 2017) by international standards as Singapore is still listed as one of the countries not having a child abuse registry in the U.S. Citizenship and Immigration Services for Child Abuse Registries in Foreign Countries and geographic Entities.

\subsubsection{Creation of a Child Abuse Registry}

Given the increasing trend in child abuse and the wide socio-economic ramifications it is important to create a comprehensive Child Abuse Registry (Registry) in accordance with international standards, accessible to a wider group than current stakeholders (U.S. Department of Health and Human Services, 2003).

\subsubsection{Accessibility}

The Registry should be centralized and comprehensive on the details. It should contain details of the alleged perpetrator, victim, family members/care givers and details of the child abuse incident, investigation reports \& findings and any other detail a MSF child specialists deems necessary. It should also contain details of suspected cases and follow-up, review and perhaps investigation findings of such cases. For the latter, the Registry should act as an amber alert for suspected cases so that the appropriate intervention measures can be activated promptly when the situation arises.

This Registry should be accessible by the following:

- Police;

- Healthcare professionals;

- Senior designated persons and/or principals in schools, child care business etc.;

- Designated MSF officers.

\subsubsection{Purpose}

Having such a Registry can serve multiple purposes. First it can act as an effective alert system to a wider network of stakeholders so that prompt attention can be taken for intervention measures, if necessary. Second the details in such a Registry accessible to designated educators can serve to advocate safe recruitment practices in schools. Perhaps it can be mandated that a check of the central registry be done of individuals applying to be a CYP provider. Currently a school is 
dependent on the declarations made by the applicant with respect to offences committed and investigations done against him/her. This is not necessarily full proof.

Next it may bring to forefront details of parents or care-givers who may have abused CYP and to avoid detection of child abuse are changing schools.

Such a Registry will allow medical professionals charged with the medical care of abused CYP, to maintain close surveillance of the CYP and the home environment after discharge. Medical professionals specializing in the area of child abuse and vested with the care of such CYP may find such a Registry useful for tracking parents of child abuse, and the CYP to monitor the well-being of the latter. In a study conducted to examine the demographics, social characteristics, medical, developmental and behavioral profile of CYP subject of abuse, it was found that a sizeable proportion of the CYP were victims of repeated child abuse requiring hospitalization (Ngiam et al., 2015). Hence the report suggested that perhaps the causes of the child abuse were not adequately resolved (Ngiam et al., 2015). Thus a recommendation was made that "there was a need to carefully assess the safety of the home environment and maintain close surveillance of these children and families following discharge" (Ngiam et al., 2015). A Registry containing the relevant details will allow such close surveillance of the CYP and the home environment (Ngiam et al., 2015). Additionally it was mentioned that CYPs with history of child abuse may exhibit developmental problems such as ADHD. That was discovered to be the common developmental problem of the CYPs subject of the study. Hence it was recommended that CYPs with history of abuse be screened for developmental problems (Ngiam et al., 2015). In such instances, the Registry with the necessary details may facilitate appropriate diagnosis followed by appropriate patient care treatment. It is patent that ADHD can have a negative societal and economic impact where the individual is not able to perform well at work due to his/her condition.

\subsection{Sports Registry}

With respect to the current national registry for coaches of sports, registration must be made compulsory for compliance reasons. Thus all sports coaches, full time or otherwise must be subject to compulsory registration under the registry. This registry must be integrated with the Singapore Athletics, which is not the case now. Otherwise there will be gaps in the system due to lack of integration which will allow a perpetrator to go unnoticed. Such a registration system will also focus on adding refresher courses on ethics of playing sports free of abuse, since current membership requires the coaches to have undertaken a course on values and principles in sports. Additionally at the institutional level, compulsory training for sports coaches can be instituted to address ethics of sports free of abuse and also to educate them into becoming a reporter in cases of CYP abuse in the home environment. Such a registry will facilitate safe recruitment practices for sports coaches. However this is not a full proof system as ultimately the responsibility to behave in an ethical and lawful manner remains with the 
sports coach..$^{56}$

\section{Conclusion}

Child abuse has wide ramifications on the CYP's well-being, society and economy, carrying huge economic costs. Child abuse is a serious issue with wide ramifications for the child, society and the system. It needs to be dealt with at the earliest opportune moment. Child abuse in Singapore has been on the rise for the last three years (Tan, 2017). ${ }^{57}$ On $30^{\text {th }}$ November 2017, it was reported that the Court of Appeal in Singapore had asked Parliament to consider giving judges the power to mete out enhanced punishment for child abuse cases to send a strong deterrence message. Singapore has implemented a good CYP protection system but as always we never rest on our laurels. As a country we are known to continue to strive harder and better. Enhancements suggested above are necessary so that future generations are not affected in a rapidly aging society, like Singapore.

\section{References}

Brottsoffermyndigheten (2015). Liten och trgg-en handledning för förskolan. http://www.jagvillveta.se/forskola

California Penal Code, Child Abuse and Neglect Reporting Act, Sections 11164-11174.3. http://leginfo.legislature.ca.gov/faces/codes_displayText.xhtml?lawCode=PEN\&divisio $\underline{\mathrm{n}}=$ \&title $=1 . \& \mathrm{part}=4 . \&$ chapter $=2$. . $\operatorname{article}=2.5$

Goh, L. G. (2011). Management of Child Abuse in Singapore. The Singapore Family Physician, 37, 17-24.

Goy, T. (2017). Nearly $40 \%$ of Children in Abuse Cases under Age Seven. The Straits Times.

http://www.straitstimes.com/singapore/nearly-40-of-children-in-abuse-cases-under-ag e-seven

Kansas Statues (2012). Mandated Reporters, K.S.A. 38-2223.

http://kslegislature.org/li_2012/m/statute/038_000_0000_chapter/038_022_0000_articl e/038_022_0023_section/038_022_0023_k.pdf

Ministry for Social and Family Development (2016b). Protecting Children in Singapore, 1-46.

https://www.msf.gov.sg/publications/Pages/Protecting-Children-in-Singapore.aspx

Ministry of Social and Family Development (2003). Good Practices Handbook for Child Care Centres, 1-104.

https://www.msf.gov.sg/publications/Pages/Good-Practices-Handbook-for-Child-Care -Centres.aspx

Ministry of Social and Family Development (2015). Sector-Specific Screening Guide: Education, Implementation Version 1.0, Updated July 2016, 1-23.

https://www.childcarelink.gov.sg/ccls/uploads/sssg-education-final-pp-manual.pdf

Ministry of Social and Family Development (2016a). National Standards for Protection of Children, 1-32.

https://www.msf.gov.sg/publications/Pages/National-Standards-for-Protection-of-Chil

\footnotetext{
${ }^{56}$ See, e.g., Serani (2011) and Wikipedia (2017) on sexual abuse in the aspect of sports and more specifically, the recent revelation of sexual abuse amongst students in soccer coaching in the UK.

${ }^{57}$ See also Goy (2017), where it was reported that of the reported cases nearly $40 \%$ of the children were below 7 years of age.
} 
dren.aspx

Ngiam, X. Y., Kang, Y. Q., Ramkumar, A., King, J., \& Chung, E. (2015). Child Maltreatment Syndrome: Demographics and Developmental Issues of Inpatient Cases. Singapore Medical Journal, 56, 612-617. https://doi.org/10.11622/smedj.2015169

Public Prosecutor v BDB [2017] SGCA 69.

Serani, D. (2011). Sexual Abuse in Sports. Psychology Today. https://www.psychologytoday.com/blog/two-takes-depression/201112/sexual-abuse-insports

Singapore Ministry of Education (2017). Teach. https://www.moe.gov.sg/careers/teach

Singapore Ministry of Law (2017). Public Consultation on Proposed Amendments to Criminal Procedure Code and Evidence Act.

https://www.mlaw.gov.sg/content/minlaw/en/news/press-releases/public-consultationon-proposed-amendments-to-the-criminal-proce.html

Singapore Parliamentary Debates, Official Report (18 January 1993) Vol 60, cols 449-450, 452-454.

Sport Singapore (2017). Athletes and Coaches. https://www.sportsingapore.gov.sg/athletes-coaches

Tan, T. (2017). Spike in Child Abuse. The Straits Times. http://www.straitstimes.com/singapore/spike-in-child-abuse

The Kansas Department for Children and Families (Revised 2016). A Guide to Reporting Child Abuse and Neglect, 1-23.

http://www.dcf.ks.gov/services/PPS/Documents/GuidetoReportingAbuseandNeglect.p df

The Statutes of the Republic of Singapore (2008). Penal Code (Cap 224).

The Statutes of the Republic of Singapore (2009). Women's Charter (Cap 353).

The Statutes of the Republic of Singapore, Children and Young Persons Act, Rev. Ed. Cap 38 (2001).

The Statutes of the Republic of Singapore, Criminal Procedure Code, Rev. Ed. Cap 68 (2012).

The Statutes of the Republic of Singapore, Early Childhood Development Centres Act 2017, No 19 (2017).

The Statutes of the Republic of Singapore, Evidence Act, Rev. Ed. Cap 97 (1997).

U.S. Citizenship and Immigration Services (2017). Child Abuse Registries in Foreign Countries and Geographic Entities: Countries and Geographic Entities with No Available Child Abuse Registries.

https://www.uscis.gov/adoption/home-study-information/child-abuse-registries-foreig n-countries-and-geographic-entities

U.S. Department of Health and Human Services (2003). Child Abuse and Neglect User Manual Series: The Role of Educators in Preventing and Responding to Child Abuse and Neglect. https://www.childwelfare.gov/pubPDFs/educator.pdf

United Nations (1989). Convention on the Rights of the Child. Adopted and Opened for Signature, Ratification and Accession by General Assembly Resolution.

Wikipedia (2017). United Kingdom Football Sexual Abuse Scandal. https://en.wikipedia.org/wiki/United_Kingdom_football_sexual_abuse_scandal 